\title{
Specialist teams as constituted are unsatisfactory for treating people with personality disorders
}

\author{
Conor Duggan, ${ }^{1}$ Peter Tyrer $^{2,3}$ (1)
}

BJPsych Bulletin (2022) 46, 100-102, doi:10.1192/bjb.2021.69

1University of Nottingham, UK; ${ }^{2}$ Lincolnshire Partnership NHS Foundation Trust, Lincoln, UK; ${ }^{3}$ mperial College, London, UK

Correspondence to Peter Tyrer (p.tyrer@imperial.ac.uk)

First received 12 May 2021, final revision 7 Jun 2021, accepted 22 Jun 2021

(c) The Author(s), 2021. Published by Cambridge University Press on behalf of the Royal College of Psychiatrists. This is an Open Access article, distributed under the terms of the Creative Commons Attribution-NonCommercialNoDerivatives licence (http:// creativecommons.org/licenses/by-ncnd/4.0/), which permits noncommercial re-use, distribution, and reproduction in any medium, provided the original work is unaltered and is properly cited. The written permission of Cambridge University Press must be obtained for commercial re-use or in order to create a derivative work.
Summary It is now becoming standard practice in most advanced economies to provide specialist services for those with personality disorder. Such services, almost exclusively, provide complex well-structured psychological interventions lasting many months for a small number of those with borderline personality disorder pathology. The evidence suggests that these treatments are effective but they can only be provided for a small number of people. However, in every area the numbers of patients with significant personality disorder far exceeds those that are treated, and most of these have other personality disorders. It is argued that the current service system is not working efficiently and should be replaced by one that provides resources and expertise within community teams with some external advice from specialists but no transfer of responsibility to a designated team.

Keywords Personality disorder; community mental health teams; psychosocial interventions; comorbidity; supervision.
In 2003 the now well-referenced and praised Department of Health booklet Personality Disorder: No Longer a Diagnosis of Exclusion made a number of statements about the development of new services that were being set up across the country at that time. This included:

'Good practice indicates that service provision for personality disorder can most appropriately be provided by means of:

- the development of a specialist multidisciplinary personality disorder team to target those with significant distress or difficulty who present with complex problems

- the development of specialist day services in areas with high concentrations of morbidity."1

This advice has been followed for the subsequent 18 years and reinforced by National Institute for Health and Care Excellence (NICE) guidelines in $2009 .^{2}$ We believe it to be false, despite it being made in good faith, and a re-evaluation is needed.

\section{Problems with current practice}

Most parts of England now have a service devoted, if not dedicated, to the care of people with personality disorders. ${ }^{3}$ Although this is probably unique in providing the only national service for personality disorders in the world, it is not working too well. The notion behind these specialist services seems logical. Community mental health teams (CMHTs), at least initially, provide care for the main service-seeking group, those with emotionally unstable personality disorder (EUPD). But they are neither sufficiently skilled nor properly resourced for this task, so the obvious response is to refer them on to a specialist service. Unfortunately, this referral is not always successful, either because the appropriate specialist service is not available (very few offer comprehensive treatments) or it is judged that patients lack the psychological maturity to benefit from such an intervention. Rejections are frequent and this undermines the notion of 'no longer a diagnosis of exclusion'. There can also be long delays and many bureaucratic hurdles to overcome before patients start treatment even if they are deemed suitable for one of the specialist treatments, mainly mentalisation-based treatment, dialectical behaviour therapy (DBT) or cognitive approaches. The experiences of patients in trying to access these services has promoted anger and also stigma, as many who feel rejected by these services for any reason blame the label of personality disorder and its incompetent adherents for their lack of care. ${ }^{4}$

\section{Readiness for referral}

An intervention to anticipate the delay has been suggested in this journal based on a transtheoretical model of change so as to 'guide how to increase readiness for referral and when to 
refer' ${ }^{5}$ This is complicated, including psycho-education about EUPD, personal formulation, crisis planning, motivational interviewing and several other things. But many will fail to negotiate this particular steeplechase of fences. At that point it is frankly ridiculous to expect the CHMT to provide further informed care. This inevitably leads to disenchantment on both sides; patients feel dissatisfied and are increasingly looking for interventions outside the standard systems to satisfy their needs ${ }^{4}$ and CMHTs feel disempowered while at the same time being 'stuck' with patients who are reluctant to engage.

\section{The alternative view}

A good service for those with personality disorder should be able to provide continuity of care and be able to engage with all those who have personality disorder. Currently, mental health professionals have a fixation with emotionally unstable personality disorder (EUPD) or its DSM equivalent, borderline personality disorder (BPD). This is understandable; it accounts for virtually all published guidelines ${ }^{6}$ and completely neglects the $84 \%$ of people with other personality disorders identified in national studies. ${ }^{7}$ There is another reason for paying more attention to the other personality disorders: their long-term outcome is currently less good than that for borderline personality disorder. ${ }^{8,9}$

\section{Specialist services for EUPD}

So why does EUPD get all the attention? It is because it is the quintessential 'treatment-seeking' personality disorder (i.e. a type S personality disorder), in contrast to the majority of type $\mathrm{R}$ personality disorders, which are treatment rejecting. ${ }^{10}$ But treatment seeking should not be the only consideration. When services were being reconfigured to provide for those with personality disorder, a reliance on specialist services was unsurprising as these appeared to be underpinned by research evidence. But evidence is now changing. None of the systematic reviews of psychological treatments for personality disorder show compelling evidence of superiority of one psychological therapy over another or, indeed, when the specialist therapy was compared against good-quality clinical care.

\section{Community mental health teams: a service for all with personality disorders}

A good CMHT has: (a) a range of skills that can deal with a wide range of psychopathology, including managing many with comorbid mental illnesses; (b) stability, so that the team will provide continuity of care despite the loss of key individuals; (c) capacity to engage and contain individuals who are treatment resistant - given their experience in providing for those with severe mental illness; and (d) a closer link to general practice than specialist services.

Despite these advantages, nobody can be unaware of the pressures on CMHTs and so any additional service provision requires more training and resources if it is to be successful. In this context, services should be aware that significant funding is coming to community mental health services in the next 2 years (Tim Kendall of NHS England has pointed out that this funding includes a ring-fenced sum of $£ 1.3$ million for each 50000 population group for community mental health and crisis-related services (T. Kendall, personal communication with permission, 2 June 2021)). This is genuinely new money and all should be prepared for this bonanza and ready and able to spend it wisely. This extra funding should enable a CMHT to include training in a simple assessment procedure that will allow it to separate those with significant personality disorder from those with lesser personality difficulties. Fortunately, the simple classification by severity in the new ICD-11 classification ${ }^{11}$ is suitable for this task and straightforward scales are available to help with diagnosis. ${ }^{12,13}$ Patients with personality disorder who are not treatment seeking currently account for a disproportionate proportion of total costs $^{14}$ and to fail to address their extra needs is negligent.

The procedure adopted by each trust could be along the following lines:

(a) one or more members of the CMHT are trained in the principles of identification and management of personality disorders

(b) on entry to the team each patient has their personality function assessed

(c) the trained CMHT members will take over the carecoordinating role for the patients with the more severe disorders

(d) when needed, a separate team with expertise in psychological treatments can be called in for advice and guidance, adding elements of the specialist interventions such as DBT but not involving taking over care from the CMHT

(e) the specialist team has an oversight role for patients with personality disorder in any part of care; this may often be particularly important when in-patient care is needed

(f) relevant information and care plans from the CMHT services will be shared more closely with primary care and crisis resolution teams, and day services when necessary, so that discontinuity in care can be reduced as much as possible

(g) greater use is made of primary care services and additional resources such as social prescribing, which has great potential in this group of patients but has been insufficiently embraced in mental health. ${ }^{15}$

The advantage of this arrangement is that all personality disorders are recognised, including the Galenic syndromes ${ }^{16}$ (closely intertwined mental state and personality disorders, named after Galen, who first postulated the link between personality and disease) such as substance misuse, impulsive disorders and anxiety and avoidant disorders (the general neurotic syndrome). Continuity of care and informed feedback are also more likely when patients are transferred to different parts of the services, and there is also much better transition from secondary to primary care.

This is the way forward, not the further accumulation of specialist teams.

\section{About the authors}

Conor Duggan is Emeritus Professor of Forensic Psychiatry in the Division of Psychiatry and Applied Psychology and the Institute of Mental Health at the University of Nottingham, UK. Peter Tyrer is a consultant in transformation 
psychiatry with Lincolnshire Partnership NHS Foundation Trust, Lincoln, and Emeritus Professor of Community Psychiatry at Imperial College's Division of Psychiatry, London, UK

\section{Data availability}

Data availability is not applicable to this article as no new data were created or analysed in this study.

\section{Acknowledgments}

We thank Jo Emmanuel, Tim Kendall and Fatema Ibrahimi for advice in the preparation of this article.

\section{Author contributions}

C.D. wrote the first draft of this article; this was added to by P.T.. Both authors approved the final manuscript.

\section{Funding}

This research received no specific grant from any funding agency, commercial or not-for-profit sectors.

\section{Declaration of interest}

P.T. is the co-editor of the Against the Stream series and on the Editorial Board of BJPsych Bulletin but had no part in the review or assessment of this article.

\section{References}

1 National Institute for Mental Health in England. Personality Disorder: No Longer a Diagnosis of Exclusion. Department of Health, 2003: p. 7.

2 National Institute for Health and Care Excellence. Borderline Personality Disorder: Recognition and Management (NICE Clinical Guideline CG78). NICE, 2009.

3 Dale O, Sethi F, Stanton C, Evans S, Barnicot K, Sedgwick R, et al. Personality disorder services in England: findings from a national survey. BJPsych Bull 2017; 41: 247-53.
4 Ramsden J, Prince S, Blazdell J (eds) Working Effectively with 'Personality Disorder': Contemporary and Critical Approaches to Clinical and Organizational Practice. Pavilion Publishing and Media, 2020.

5 Roughley M, Maguire A, Wood G, Lee T. Referral of patients with emotionally unstable personality disorder for specialist psychological therapy: why, when and how? BJPsych Bull 2021; 45: 52-8.

6 Simonsen BA, Bateman A, Bohus M, Dalewijk HJ, Doering S, Kaera A et al. European guidelines for personality disorders: past, present and future. Borderline Pers Disord Emot Dysregulation 2019; 6: 9.

7 Coid JW, Yang M, Tyrer P, Roberts A, Ullrich S. Prevalence and correlates of personality disorder in Great Britain. Br J Psychiatry 2006; 188 423-31.

8 Álvarez-Tomas I, Ruiz J, Guilera G, Bados A. Long-term clinical and functional course of borderline personality disorder: a meta-analysis of prospective studies. Eur Psychiatry 2019; 56: 75-83.

9 Yang $M$, Tyrer $H$, Johnson $T$, Tyrer $P$. Personality change in the Nottingham Study of Neurotic Disorder: 30 year cohort study. Aust NZ J Psychiatry 2021; in press.

10 Tyrer $P$, Mitchard S, Methuen C, Ranger $M$. Treatment rejecting and treatment seeking personality disorders. J Personal Dis 2003; 17: 263-8.

11 Tyrer $P$, Mulder R, Kim Y-R, Crawford MJ. The development of the ICD-11 classification of personality disorders: an amalgam of science, pragmatism and politics. Ann Rev Clin Psychol 2019; 15: 481-502.

12 Bach B, Brown TA, Mulder RT, Newton-Howes G, Simonsen E, Selbom M Development and initial evaluation of the ICD-11 personality disorder severity scale: PDS-ICD-11. Pers Ment Health [Epub ahead of print] 17 May 2021. Available from: https://doi.org/10.1002/pmh.1510.

13 Kim Y-R, Tyrer P, Hwang S-T. Personality Assessment Questionnaire for ICD-11 personality trait domains: development and testing. Pers Ment Health 2021; 15: 58-71.

14 Lenzenweger MF, Lane MC, Loranger AW, Kessler RC. DSM-IV personality disorders in a National Comorbidity Survey Replication. Biol Psychiatry 2007; 62: 553-64.

15 Maughan DL, Patel A, Parveen T, Braithwaite I, Cook J, Lillywhite R, et al. Primary-care-based social prescribing for mental health: an analysis of financial and environmental sustainability. Prim Health Care Res Dev 2016; 17: 114-21.

16 Tyrer P, Mulder R. Personality Disorders: From Evidence to Understanding. Cambridge University Press, 2021; in press.

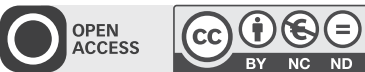

